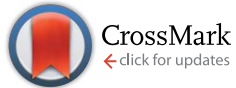

Cite this: RSC Adv., 2015, 5, 67979

\title{
Luminescence and energy transfer of co-doped $\mathrm{Sr}_{5} \mathrm{MgLa}_{2}\left(\mathrm{BO}_{3}\right)_{6}: \mathrm{Ce}^{3+}{ }_{,} \mathrm{Mn}^{2+}$
}

\author{
Matthias Müller, Stefan Fischer and Thomas Jüstel*
}

In this work the photoluminescence (PL) of co-doped $\mathrm{Sr}_{5} \mathrm{MgLa}_{2}\left(\mathrm{BO}_{3}\right)_{6}: \mathrm{Ce}^{3+}, \mathrm{Mn}^{2+}$ as well as the energy transfer (ET) from $\mathrm{Ce}^{3+}$ to $\mathrm{Mn}^{2+}$ was examined. To this end, powder samples with different $\mathrm{Mn}^{2+}$ concentrations were synthesised via high temperature solid state reaction. Phase purity of prepared samples was investigated by $\mathrm{X}$-ray powder diffraction. To elucidate the $\mathrm{PL}$ properties of $\mathrm{Sr}_{5} \mathrm{MgLa}_{2}\left(\mathrm{BO}_{3}\right)_{6}: \mathrm{Ce}^{3+}, \mathrm{Mn}^{2+}$, emission and excitation spectra along with diffuse reflectance spectra were recorded. Additionally, fluorescence lifetime measurements were performed. To study the temperature behaviour of the emission of $\mathrm{Sr}_{5} \mathrm{MgLa}_{2}\left(\mathrm{BO}_{3}\right)_{6}: \mathrm{Ce}^{3+}, \mathrm{Mn}^{2+}, \mathrm{PL}$ and lifetime measurements were conducted from 100 to $500 \mathrm{~K}$. Furthermore, external quantum efficiencies were determined and chromaticity coordinates were calculated. It was found that co-doped $\mathrm{Sr}_{5} \mathrm{MgLa}_{2}\left(\mathrm{BO}_{3}\right)_{6}: \mathrm{Ce}^{3+}, \mathrm{Mn}^{2+}$ possesses two emission bands located in the violet/blue and deep red range of the electromagnetic spectrum. Moreover, it turned out that ET from $\mathrm{Ce}^{3+}$ to $\mathrm{Mn}^{2+}$ in $\mathrm{Sr}_{5} \mathrm{MgLa}_{2}\left(\mathrm{BO}_{3}\right)_{6}: \mathrm{Ce}^{3+}, \mathrm{Mn}^{2+}$ takes place via an exchange interaction mechanism. Temperature dependent PLD measurements reveal that thermal quenching of emission is mainly caused by the $\mathrm{Mn}^{2+}$ ions. Finally, quantum efficiency of $\mathrm{Ce}^{3+}$ doped $\mathrm{Sr}_{5} \mathrm{MgLa}_{2}\left(\mathrm{BO}_{3}\right)_{6}: \mathrm{Ce}^{3+}$ was found to be close to unity.

Received 3rd July 2015

Accepted 28th July 2015

DOI: $10.1039 / c 5 r a 12951 f$

www.rsc.org/advances

\section{Introduction}

In the last two decades light emitting diodes (LEDs) have more and more replaced conventional light sources like incandescent or fluorescent lamps. This is due to the benefits LEDs provide to lighting installations over traditional light sources. Commonly, LEDs provide longer lifetime, higher wall plug efficiency, as well as a higher colour rendering. ${ }^{1}$ Nowadays most of the white emitting LEDs consist of a blue emitting (In,Ga)N-chip combined with a green-yellow emitting phosphor, e.g. $\mathrm{Y}_{3} \mathrm{Al}_{5} \mathrm{O}_{12}: \mathrm{Ce}^{3+}{ }^{2}$ These light sources provide high luminous efficiency due to intense emission in the green spectral range. On the other site, due to the lack of red emission these systems suffer from a high colour temperature and low colour rendering index (CRI) which is unintended for domestic lighting. ${ }^{3}$ On that account an alternative approach to generate warm white light with appropriate CRI is the combination of a blue, green, and red phosphor excited by an ultraviolet (UV) emitting LED. In this way LEDs with excellent colour temperature as well as convenient CRI can be designed. ${ }^{4}$ Unfortunately, these packages incur a loss in blue emission due to reabsorption by the green and red phosphors. This is why many groups try to develop single phase white emitting phosphors which convert UV radiation into white light. ${ }^{5}$ One strategy to realize such a phosphor is to use the ion couple $\mathrm{Ce}^{3+}$ and $\mathrm{Mn}^{2+} \cdot{ }^{6}$ In many host materials $\mathrm{Ce}^{3+}$ and $\mathrm{Mn}^{2+}$ possess broad

Department of Chemical Engineering, Münster University of Applied Sciences, Stegerwaldstrasse 39, 48565 Steinfurt, Germany.E-mail: tj@fh-muenster.de emission bands in the blue and red spectral range, respectively. ${ }^{7}$ Due to additive colour mixing these emission bands can complement each other to white light. Further, the broad excitation band of the spin and parity allowed $[\mathrm{Xe}] 4 \mathrm{f}^{1}-[\mathrm{Xe}] 5 \mathrm{~d}^{1}$ transition in $\mathrm{Ce}^{3+}$ is suitable for pumping with UV LEDs. Since all transitions in $\mathrm{Mn}^{2+}$ are fully forbidden, the blue emission of $\mathrm{Ce}^{3+}$ can also be used for sensitizing the $[\mathrm{Ar}] 3 \mathrm{~d}^{5}-[\mathrm{Ar}] 3 \mathrm{~d}^{5}$ excitation transition via energy transfer (ET).

To investigate the photoluminescence (PL) properties as well as the ET from $\mathrm{Ce}^{3+}$ to $\mathrm{Mn}^{2+}$ in co-activated $\mathrm{Sr}_{5} \mathrm{MgLa}_{2}\left(\mathrm{BO}_{3}\right)_{6}: \mathrm{Ce}^{3+}, \mathrm{Mn}^{2+}$ a series of powder samples with various $\mathrm{Mn}^{2+}$ contents was prepared. $\mathrm{Sr}_{5} \mathrm{MgLa}_{2}\left(\mathrm{BO}_{3}\right)_{6}$ belongs to a class of ortho-borates, firstly described by Schaffers et al. in 1994. ${ }^{8}$ Further, Sankar and Rao reported on the PL of different compositions of said material with numerous activators. ${ }^{9,10} \mathrm{Sr}_{5} \mathrm{MgLa}_{2}\left(\mathrm{BO}_{3}\right)_{6}$ crystalizes in a high-symmetry trigonal structure with space group $R \overline{3}$. $\mathrm{Sr}_{5} \mathrm{MgLa}_{2}\left(\mathrm{BO}_{3}\right)_{6}$ comprises a 9-fold coordinated site as well as two different octahedrally coordinated sites. The 9-fold coordinated sites are shared by $\mathrm{Sr}^{2+}$ and $\mathrm{La}^{3+}$ ions in the ratio 0.67 to 0.33 . The octahedrally coordinated sites differ in average bond length of the surrounding oxygen ions. The larger sites exhibit an average bond length of $0.2298 \AA$ and are occupied by $\mathrm{Sr}^{2+}$ ions whereas the smaller octahedral sites with a mean distance of $0.2092 \AA$ are occupied by $\mathrm{Mg}^{2+}$ ions. The ionic radii of $\mathrm{La}^{3+}$ and $\mathrm{Sr}^{2+}$ for 9-fold coordination are 1.216 and 1.13 $\AA$. $\mathrm{Sr}^{2+}$ and $\mathrm{Mg}^{2+}$ exhibit ionic radii of 1.18 and $0.72 \AA$ in an octahedral coordination. The ionic radii of $\mathrm{Ce}^{3+}$ for 9-fold and 6-fold coordination are 1.01 and $1.196 \AA$ A. 6-fold coordinated $\mathrm{Mn}^{2+}$ has 
an ionic radius of $0.83 \AA{ }^{11}$ Considering the ionic radii as well as charge balancing, it is assumed that the $\mathrm{Ce}^{3+}$ ions primarily going to occupy the 9-fold coordinated $\mathrm{La}^{3+}$ sites whereas $\mathrm{Mn}^{2+}$ ions tend to occupy the octahedral $\mathrm{Mg}^{2+}$ sites.

In this contribution, synthesis, optical properties, and ET from $\mathrm{Ce}^{3+}$ to $\mathrm{Mn}^{2+}$ in co-doped $\mathrm{Sr}_{5} \mathrm{MgLa}_{2}\left(\mathrm{BO}_{3}\right)_{6}: \mathrm{Ce}^{3+}, \mathrm{Mn}^{2+}$ are discussed. Therefore, samples with different doping concentrations were prepared via high temperature solid state synthesis. Phase purity was validated using X-ray powder diffractometry (XRD). Diffuse reflectance (DR) spectra were recorded to examine the body colour of $\mathrm{Sr}_{5} \mathrm{MgLa}{ }_{2}\left(\mathrm{BO}_{3}\right)_{6}: \mathrm{Ce}^{3+}, \mathrm{Mn}^{2+}$. PL properties were investigated by recording PL spectra and photoluminescence excitation spectra (PLE). Temperature behaviour of the PL was examined by recording PL spectra from 100 to $500 \mathrm{~K}$. In addition, photoluminescence decay (PLD) measurements were performed from 100 to $500 \mathrm{~K}$ to study the origin of thermal quenching. To monitor the ET from $\mathrm{Ce}^{3+}$ to $\mathrm{Mn}^{2+}$ PLD measurements were performed on samples with different $\mathrm{Mn}^{2+}$ concentrations. Furthermore, external quantum efficiencies $\eta_{\text {ext }}$ were determined and chromaticity coordinates according to Commission International de l'Eclairage 1931 (CIE) were calculated.

\section{Experimental}

All investigated $\mathrm{Sr}_{5} \mathrm{MgLa}_{2}\left(\mathrm{BO}_{3}\right)_{6}: \mathrm{Ce}^{3+}, \mathrm{Mn}^{2+}$ samples were prepared by high temperature solid state synthesis. To this end, high purity educts $\mathrm{SrCO}_{3}$ (Aldrich, 99.9\%), MgO (Merck KGaA, p.a.), $\mathrm{La}_{2} \mathrm{O}_{3}$ (Treibacher Industrie AG, 99.995\%), $\mathrm{H}_{3} \mathrm{BO}_{3}$ (Merck KGaA, Ph. Eur.), $\mathrm{CeO}_{2}$ (Atomergic Chemetals Co., 99.9\%), and $\mathrm{MnC}_{2} \mathrm{O}_{4} \cdot 2 \mathrm{H}_{2} \mathrm{O}$ (Dr Paul Lohmann, chem. pure) were weighted in stoichiometric amounts. Though, an excess of $5 \%$ of boric acid was used to compensate evaporation. The starting materials were thoroughly blended in acetone in an agate mortar. After drying at ambient temperatures, the obtained powder blends were heated at $650{ }^{\circ} \mathrm{C}$ for $1 \mathrm{~h}$ in air to decompose the boric acid. Afterwards, the samples were ground and calcined at $1200{ }^{\circ} \mathrm{C}$ for $6 \mathrm{~h}$ in a corundum crucible imbedded in active carbon. Obtained white sinter bodies were subsequently ground to a fine $\mu$-powder.

Phase purity of the synthesized $\mathrm{Sr}_{5} \mathrm{MgLa}_{2}\left(\mathrm{BO}_{3}\right)_{6}: \mathrm{Ce}^{3+}, \mathrm{Mn}^{2+}$ samples was investigated using XRD. XRD patterns were collected on a Rigaku MiniFlex II diffractometer working in Bragg-Brentano geometry using $\mathrm{Cu} \mathrm{K}_{\alpha}$ radiation. Step width and integration time were set to $0.02^{\circ}$ and $1 \mathrm{~s}$, respectively.

PL spectra as well as PLE spectra were recorded on an Edinburgh Instruments FSL900 spectrometer equipped with a Xe arc lamp $(450 \mathrm{~W})$ and a cooled $\left(-20{ }^{\circ} \mathrm{C}\right)$ single-photon counting photomultiplier (Hamamatsu R2658P). Obtained PL spectra were corrected by applying a correction file obtained from a tungsten incandescent lamp certified by the National Physics Laboratory U.K.

For PLD measurements on $\mathrm{Ce}^{3+}$, a picosecond pulsed LED $\left(40 \mu \mathrm{W}\right.$, pulse width $\left.=912.6 \mathrm{ps}, \lambda_{\mathrm{em}}=267 \mathrm{~nm}\right)$ was attached to the spectrometer. For PLD measurements on $\mathrm{Mn}^{2+}$ a microsecond pulsed Xe lamp $(100 \mathrm{~W}$, pulse width $=1 \mu \mathrm{s})$ was used.
PL measurements at $2.9 \mathrm{~K}$ were performed using the closed cycle cryocooler OptistatAC-V12 from Oxford Instruments. Helium was used as a cooling agent. Temperature dependent PL measurements from 100 to $500 \mathrm{~K}$ were performed using the Oxford Instruments cryostat MicrostatN2. Liquid nitrogen was used as a cooling agent. Temperature stabilization time was $60 \mathrm{~s}$ and tolerance was set to $\pm 3 \mathrm{~K}$.

DR spectra were recorded on an Edinburgh Instruments FS900 spectrometer equipped with a Xe arc lamp (450 W), a cooled $\left(-20{ }^{\circ} \mathrm{C}\right)$ single-photon counting photomultiplier (Hamamatsu R928) as well as a Teflon-coated integration sphere. $\mathrm{BaSO}_{4}$ (99.998\%, Sigma-Aldrich) was used as a reflectance standard.

External quantum efficiencies $\eta_{\text {ext }}$ were determined using the approach of Kawamura et al. ${ }^{12}$ Therefore, PL spectra of the samples as well as of the excitation source were recorded in a Teflon-coated integration sphere. From this, $\eta_{\text {ext }}$ can be calculated using the following relation:

$$
\eta_{\text {ext }}=\frac{\int I_{\text {em }}(\lambda) \mathrm{d} \lambda}{\int I_{\text {ex }}(\lambda) \mathrm{d} \lambda-\int I_{\text {ex }}^{\prime}(\lambda) \mathrm{d} \lambda}
$$

here, $I_{\mathrm{em}}(\lambda)$ is the emission intensity of the sample, $I_{\mathrm{ex}}(\lambda)$ is the intensity of the excitation lamp in absence of the sample and $I_{\text {ex }}(\lambda)$ is the intensity of the excitation lamp in presence of the sample.

\section{Results and discussion}

To investigate phase purity of the synthesised $\mathrm{Sr}_{5} \mathrm{MgLa}_{2}\left(\mathrm{BO}_{3}\right)_{6}$ samples XRD patterns were recorded. Fig. 1 shows the collected XRD patterns of doped and undoped $\mathrm{Sr}_{5} \mathrm{MgLa}_{2}\left(\mathrm{BO}_{3}\right)_{6}$ as well as the ICDD reference card of $\mathrm{Sr}_{5} \mathrm{MgLa}_{2}\left(\mathrm{BO}_{3}\right)_{6}$. The diffractograms indicate the formation of the trigonal $\mathrm{Sr}_{5} \mathrm{MgLa}_{2}\left(\mathrm{BO}_{3}\right)_{6}$ phase. No change in the host structure can be observed with increasing doping concentration. This observation confirms the suitability of the utilized synthesis route.

Fig. 2 depicts the DR spectra of undoped $\mathrm{Sr}_{5} \mathrm{MgLa}_{2}\left(\mathrm{BO}_{3}\right)_{6}$ as well as of $\mathrm{Sr}_{5} \mathrm{Mg}\left(\mathrm{La}_{0.99} \mathrm{Ce}_{0.01}\right)_{2}\left(\mathrm{BO}_{3}\right)_{6}$ and $\mathrm{Sr}_{5} \mathrm{Mg}_{0.97} \mathrm{Mn}_{0.03} \mathrm{La}_{2}\left(\mathrm{BO}_{3}\right)_{6}$. The undoped $\mathrm{Sr}_{5} \mathrm{MgLa}_{2}\left(\mathrm{BO}_{3}\right)_{6}$ sample shows an absorption band in the UV range below $400 \mathrm{~nm}$. This band is tentatively assigned to band-to-band absorption of the host structure. ${ }^{9}$ The absorption in the DR spectrum of $\mathrm{Sr}_{5} \mathrm{Mg}\left(\mathrm{La}_{0.99} \mathrm{Ce}_{0.01}\right)_{2}\left(\mathrm{BO}_{3}\right)_{6}$ is assigned to the spin and parity allowed $[\mathrm{Xe}] 4 \mathrm{f}^{1}-[\mathrm{Xe}] 5 \mathrm{~d}^{1}$ interconfigurational electric-dipole transition in $\mathrm{Ce}^{3+}$. The DR spectrum of $\mathrm{Sr}_{5} \mathrm{Mg}_{0.97} \mathrm{Mn}_{0.03} \mathrm{La}_{2}\left(\mathrm{BO}_{3}\right)_{6}$ shows slight absorption at about $470 \mathrm{~nm}$ which is ascribed to the transition from the ${ }^{6} \mathrm{~A}_{1}\left({ }^{6} \mathrm{~S}\right)$ ground state to the ${ }^{4} \mathrm{~T}_{1}\left({ }^{4} \mathrm{G}\right)$ excited state in $\mathrm{Mn}^{2+}$.

Room temperature PLE and PL spectra of singly doped $\mathrm{Sr}_{5} \mathrm{Mg}\left(\mathrm{La}_{0.99} \mathrm{Ce}_{0.01}\right)_{2}\left(\mathrm{BO}_{3}\right)_{6}$ and $\mathrm{Sr}_{5} \mathrm{Mg}_{0.97} \mathrm{Mn}_{0.03} \mathrm{La}_{2}\left(\mathrm{BO}_{3}\right)_{6}$ as well as of co-doped $\mathrm{Sr}_{5} \mathrm{Mg}_{0.90} \mathrm{Mn}_{0.10}\left(\mathrm{La}_{0.99} \mathrm{Ce}_{0.01}\right)_{2}\left(\mathrm{BO}_{3}\right)_{6}$ are depicted in Fig. 3a-c. The PLE spectrum of $\mathrm{Sr}_{5} \mathrm{Mg}\left(\mathrm{La}_{0.99} \mathrm{Ce}_{0.01}\right)_{2}\left(\mathrm{BO}_{3}\right)_{6}$ (Fig. 3a) was recorded monitoring the $400 \mathrm{~nm}$-emission and shows a broad band ranging from about 240 to $370 \mathrm{~nm}$. This band consists of various unresolved bands due to excitation 


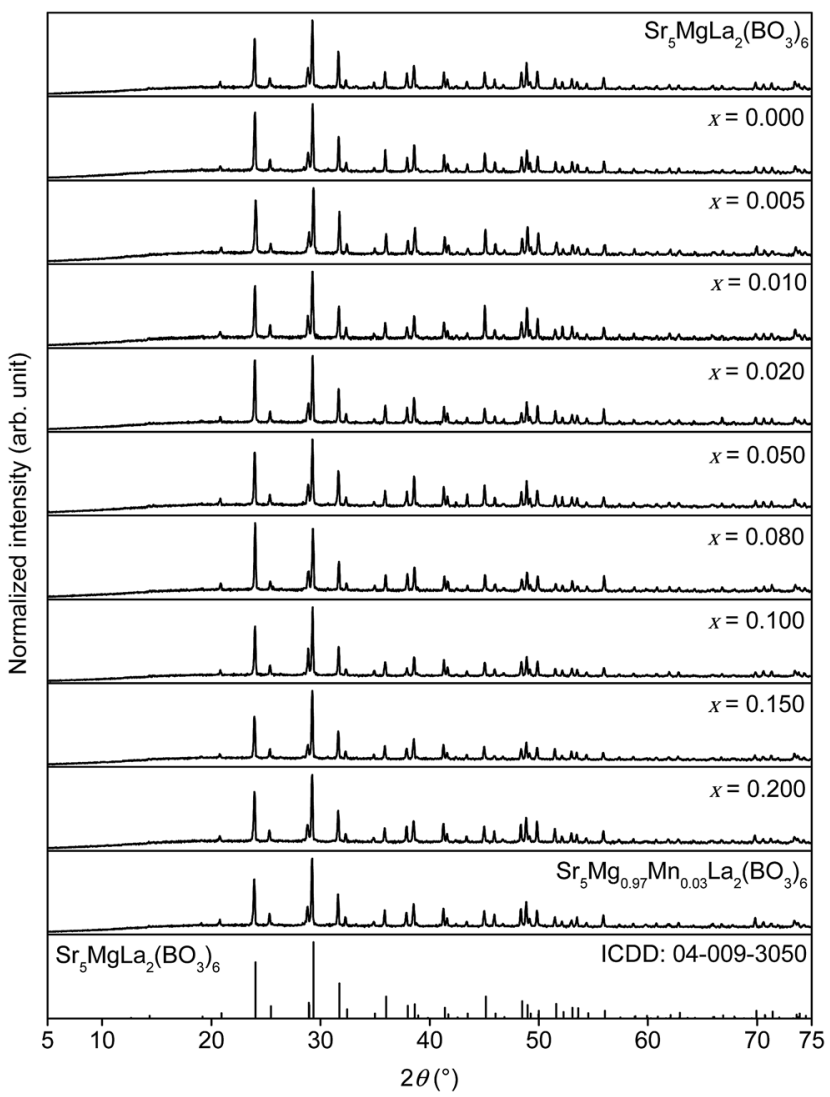

Fig. 1 XRD patterns of $\mathrm{Sr}_{5} \mathrm{MgLa}_{2}\left(\mathrm{BO}_{3}\right)_{6}, \mathrm{Sr}_{5} \mathrm{Mg}_{1-x} \mathrm{Mn}_{x}\left(\mathrm{La}_{0.99} \mathrm{Ce}_{0.01}\right)_{2}\left(\mathrm{BO}_{3}\right)_{6}$, $\mathrm{Sr}_{5} \mathrm{Mg}_{0.97} \mathrm{Mn}_{0.03} \mathrm{La}_{2}\left(\mathrm{BO}_{3}\right)_{6}$, and ICDD reference card.

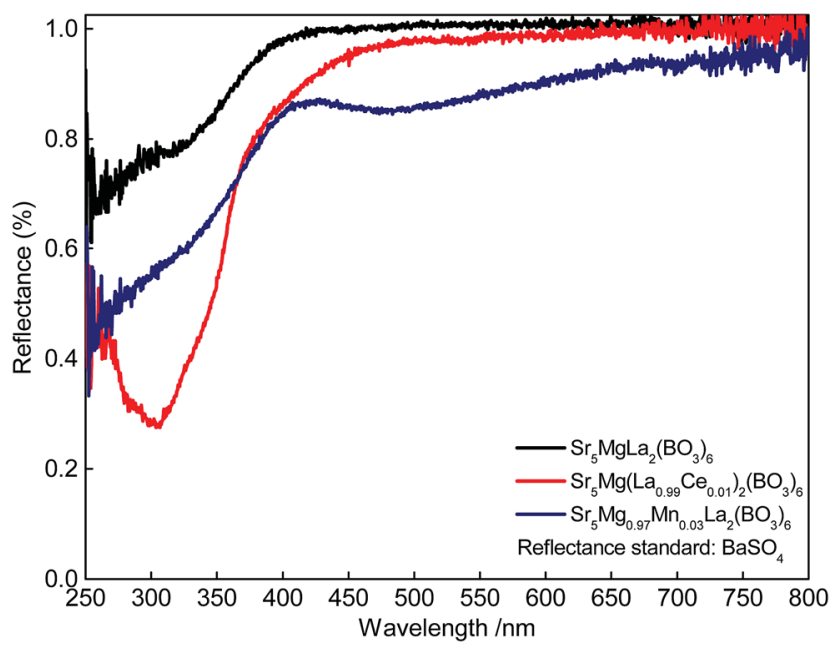

Fig. 2 DR spectra of $\mathrm{Sr}_{5} \mathrm{MgLa} 2\left(\mathrm{BO}_{3}\right)_{6}, \mathrm{Sr}_{5} \mathrm{Mg}\left(\mathrm{La}_{0.99} \mathrm{Ce}_{0.01}\right)_{2}\left(\mathrm{BO}_{3}\right)_{6}$, and $\mathrm{Sr}_{5} \mathrm{Mg}_{0.97} \mathrm{Mn}_{0.03} \mathrm{La}_{2}\left(\mathrm{BO}_{3}\right)_{6}$.

from the ${ }^{2} \mathrm{~F}_{7 / 2,5 / 2}$ ground state to the $[\mathrm{Xe}] 5 \mathrm{~d}^{1}$ multiplet of $\mathrm{Ce}^{3+}$. The PL spectrum of $\mathrm{Sr}_{5} \mathrm{Mg}\left(\mathrm{La}_{0.99} \mathrm{Ce}_{0.01}\right)_{2}\left(\mathrm{BO}_{3}\right)_{6}$ was recorded using an excitation wavelength of $\lambda_{\mathrm{ex}}=300 \mathrm{~nm}$. The spectrum exhibits a broad band peaking at about $397 \mathrm{~nm}$ and a tailing towards lower energy of the electromagnetic range. This emission band occurs due to radiative relaxation from the excited ${ }^{2} D_{j}$ state of the $[\mathrm{Xe}] 5 \mathrm{~d}^{1}$ configuration to the ${ }^{2} \mathrm{~F}_{7 / 2,5 / 2}$ ground state of $\mathrm{Ce}^{3+}$. The tailing is caused by $\mathrm{Ce}^{3+}$ ions occupying different lattice sites and will be discussed later in the article in more detail. Fig. $3 \mathrm{~b}$ illustrates the PLE and PL spectra of $\mathrm{Sr}_{5} \mathrm{Mg}_{0.97} \mathrm{Mn}_{0.03} \mathrm{La}_{2}\left(\mathrm{BO}_{3}\right)_{6}$. Monitoring the $715 \mathrm{~nm}$-emission of $\mathrm{Mn}^{2+}$, the obtained PLE spectrum exhibits various bands at about 305, 319, 354, 378, 398, 415 and $474 \mathrm{~nm}$. These bands were attributed to transitions from the ${ }^{6} \mathrm{~A}_{1}\left({ }^{6} \mathrm{~S}\right)$ ground state to ${ }^{4} \mathrm{~T}_{1}\left({ }^{4} \mathrm{~F}\right), \quad{ }^{4} \mathrm{~A}_{2}\left({ }^{4} \mathrm{~F}\right), \quad{ }^{4} \mathrm{~T}_{1}\left({ }^{4} \mathrm{P}\right), \quad{ }^{4} \mathrm{E}\left({ }^{4} \mathrm{D}\right), \quad{ }^{4} \mathrm{~T}_{2}\left({ }^{4} \mathrm{D}\right), \quad\left[{ }^{4} \mathrm{E}\left({ }^{4} \mathrm{G}\right){ }^{4} \mathrm{~A}_{1}\left({ }^{4} \mathrm{G}\right)\right]$, and ${ }^{4} \mathrm{~T}_{1}\left({ }^{4} \mathrm{G}\right)$, respectively. The PL spectrum of $\mathrm{Sr}_{5} \mathrm{Mg}_{0.97} \mathrm{Mn}_{0.03} \mathrm{La}_{2}\left(\mathrm{BO}_{3}\right)_{6}$ shows a broad band with a maximum at about $714 \mathrm{~nm}$ and a tailing to the long wavelength range. This emission is due radiative relaxation from the ${ }^{4} \mathrm{~T}_{1}\left({ }^{4} \mathrm{G}\right)$ excited state to the ${ }^{6} \mathrm{~A}_{1}\left({ }^{6} \mathrm{~S}\right)$ ground state in $\mathrm{Mn}^{2+}$. PLE and PL spectra of $\mathrm{Sr}_{5} \mathrm{Mg}_{0.90} \mathrm{Mn}_{0.10}\left(\mathrm{La}_{0.99} \mathrm{Ce}_{0.01}\right)_{2}\left(\mathrm{BO}_{3}\right)_{6}$ are depicted in Fig. 3c. PLE spectra were recorded monitoring the emission of $\mathrm{Mn}^{2+}$ and $\mathrm{Ce}^{3+}$ at 715 and $400 \mathrm{~nm}$, respectively. The obtained PLE spectra appear similar in shape indicating the occurrence of ET from $\mathrm{Ce}^{3+}$ ions to $\mathrm{Mn}^{2+}$ ions. The PL spectrum was recorded upon excitation with a wavelength of $\lambda_{\mathrm{ex}}=300 \mathrm{~nm}$ and shows two bands peaking at about 403 and $713 \mathrm{~nm}$. These bands originate from radiative relaxation from [Xe] $5 \mathrm{~d}^{1}$ to ${ }^{2} \mathrm{~F}_{7 / 2,5 / 2}$ in $\mathrm{Ce}^{3+}$ and from ${ }^{4} \mathrm{~T}_{1}\left({ }^{4} \mathrm{G}\right)$ to ${ }^{6} \mathrm{~A}_{1}\left({ }^{6} \mathrm{~S}\right)$ in $\mathrm{Mn}^{2+}$.

For further investigations on the origin of the tailing of the $\mathrm{Ce}^{3+}$ emission band, a PL spectrum of $\mathrm{Sr}_{5} \mathrm{Mg}\left(\mathrm{La}_{0.99} \mathrm{Ce}_{0.01}\right)_{2}\left(\mathrm{BO}_{3}\right)_{6}$ was recorded at $2.9 \mathrm{~K}$. This spectrum is illustrated in Fig. 4. Commonly, $\mathrm{Ce}^{3+}$ emission consists of a doublet band due to spin-orbit-splitting of the ${ }^{2} \mathrm{~F}$ state ([Xe] $4 \mathrm{f}^{1}$ configuration) into the ${ }^{2} \mathrm{~F}_{7 / 2}$ and ${ }^{2} \mathrm{~F}_{5 / 2}$ states. The energetic difference between the ${ }^{2} \mathrm{~F}_{7 / 2}$ and ${ }^{2} \mathrm{~F}_{5 / 2}$ states usually amounts to about $2000 \mathrm{~cm}^{-1} \cdot{ }^{13}$

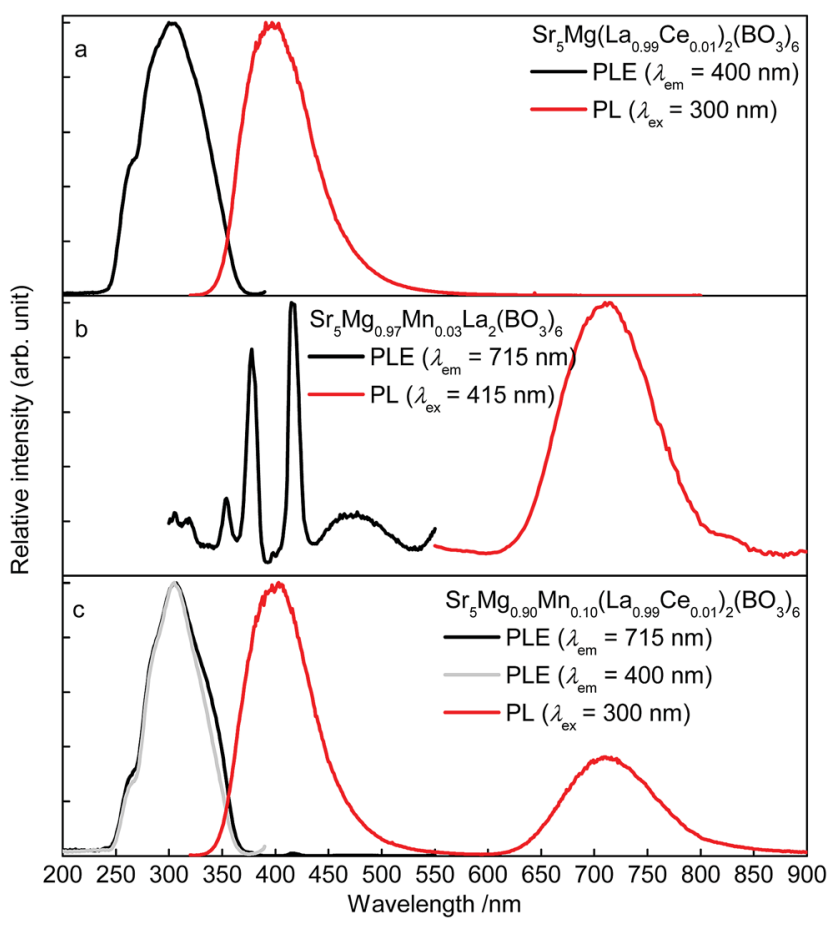

Fig. 3 Room temperature $\mathrm{PLE}$ and $\mathrm{PL}$ spectra of $\mathrm{Sr}_{5} \mathrm{Mg}\left(\mathrm{La}_{0.99} \mathrm{Ce}_{0.01}\right)_{2}\left(\mathrm{BO}_{3}\right)_{6} \quad$ (a), $\quad \mathrm{Sr}_{5} \mathrm{Mg}_{0.97} \mathrm{Mn}_{0.03} \mathrm{La}_{2}\left(\mathrm{BO}_{3}\right)_{6} \quad$ (b), $\mathrm{Sr}_{5} \mathrm{Mg}_{0.90} \mathrm{Mn}_{0.10}\left(\mathrm{La}_{0.99} \mathrm{Ce}_{0.01}\right)_{2}\left(\mathrm{BO}_{3}\right)_{6}$ (c). 
Therefore, it should be possible to fit the present $\mathrm{Ce}^{3+}$ emission band with two Gaussian curves with an approximate distance of $2000 \mathrm{~cm}^{-1}$. However, fitting the current PL spectrum with two Gaussian curves leads to an approximate distance of about $1399 \mathrm{~cm}^{-1}$. This indicates the occupation of more than one distinct crystallographic site. This is thoroughly possible since $\mathrm{Sr}_{5} \mathrm{MgLa}_{2}\left(\mathrm{BO}_{3}\right)_{6}$ provides also 6-fold coordinated $\mathrm{Sr}^{2+}$ sites aside from the 9-fold coordinated site. Against this, fitting the $\mathrm{Ce}^{3+}$ emission band with a sum of four Gaussian curves A, B, C, and D results in approximate distances of 2018 and $1979 \mathrm{~cm}^{-1}$. Based on this result, it is assumed that the $\mathrm{Ce}^{3+}$ ions also occupy the 6fold coordinated $\mathrm{Sr}^{2+}$ sites. Since crystal field splitting of the $5 \mathrm{~d}$ states decreases with increasing coordination number, the energetic difference between $\mathrm{d}$ and $\mathrm{f}$ states increases. Therefore, it is concluded that curves $\mathrm{A}$ and $\mathrm{B}$ belong to $\mathrm{Ce}^{3+}$ occupying a 6fold coordinated $\mathrm{Sr}^{2+}$ site (Ce2) whereas curves $\mathrm{C}$ and $\mathrm{D}$ were assigned to $\mathrm{Ce}^{3+}$ on a 9-fold coordinated site (Ce1). The occupation of two different crystallographic sites is also reflected in the PLE spectra depicted in the inset of Fig. 4. Monitoring the emission of $\mathrm{Ce}^{3+}$ at 345,380 , and $415 \mathrm{~nm}$ results in PLE spectra looking significantly different in shape. Shifting the monitored wavelength from 345 to $415 \mathrm{~nm}$, the obtained PLE spectrum gets broader and a new band arises. This observation also indicates PL from different crystallographic sites.

Fig. 5 depicts PL spectra of $\mathrm{Sr}_{5} \mathrm{Mg}_{1-x} \mathrm{Mn}_{x}\left(\mathrm{La}_{0.99} \mathrm{Ce}_{0.01}\right)_{2}\left(\mathrm{BO}_{3}\right)_{6}$ with $x=0.000,0.005,0.010,0.020,0.050,0.080,0.100,0.150$, and 0.200 . Up to a $\mathrm{Mn}^{2+}$ content of $x=0.100$ PL intensity of $\mathrm{Mn}^{2+}$ increases. At higher $\mathrm{Mn}^{2+}$ contents, the PL intensity of $\mathrm{Mn}^{2+}$ starts to decrease due to concentration quenching. Furthermore, with increasing $\mathrm{Mn}^{2+}$ content the $\mathrm{Ce}^{3+} \mathrm{PL}$ intensity decreases implying the occurrence of ET from $\mathrm{Ce}^{3+}$ to $\mathrm{Mn}^{2+}$.

Further, fluorescence lifetime measurements were performed monitoring the $\mathrm{Ce}^{3+}$ emission of co-doped $\mathrm{Sr}_{5} \mathrm{Mg}_{1-x} \mathrm{Mn}_{x}\left(\mathrm{La}_{0.99} \mathrm{Ce}_{0.01}\right)_{2}\left(\mathrm{BO}_{3}\right)_{6}$. The obtained PLD curves are plotted in Fig. 6 and can be best fitted with a bi-exponential function using the following equation:

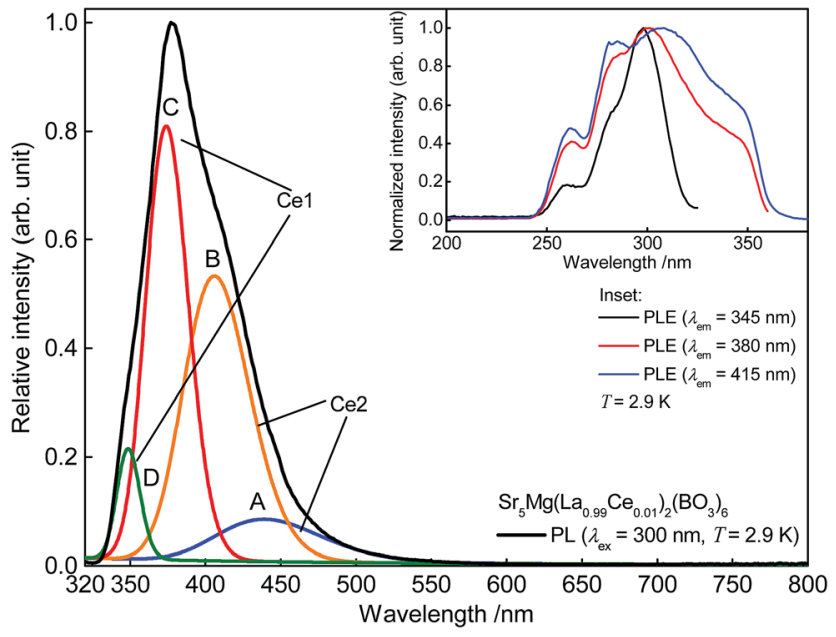

Fig. 4 Low temperature PL spectra of $\mathrm{Sr}_{5} \mathrm{Mg}\left(\mathrm{La}_{0.99} \mathrm{Ce}_{0.01}\right)_{2}\left(\mathrm{BO}_{3}\right)_{6}$ and Gaussian curves A, B, C, and D. Inset: low temperature PLE spectra of $\mathrm{Sr}_{5} \mathrm{Mg}\left(\mathrm{La}_{0.99} \mathrm{Ce}_{0.01}\right)_{2}\left(\mathrm{BO}_{3}\right)_{6}$.

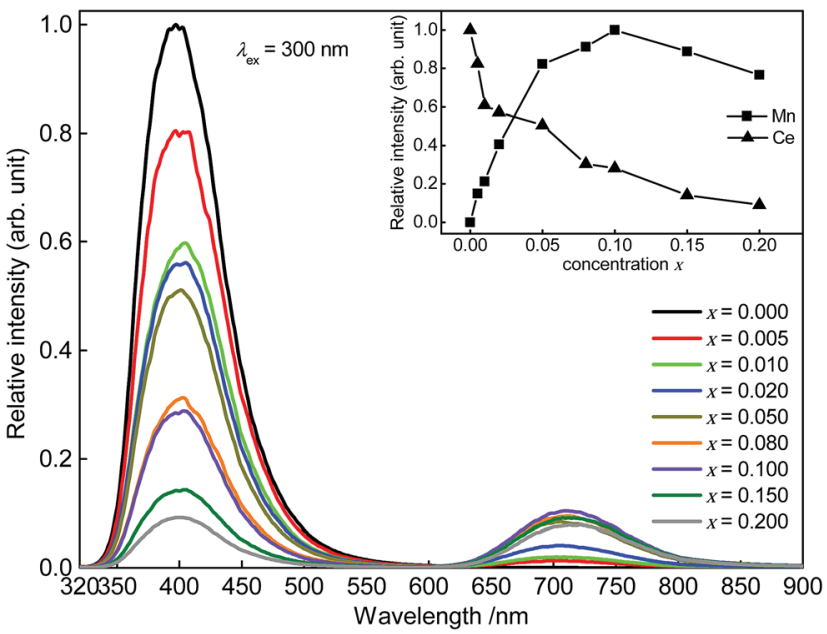

Fig. $5 \mathrm{PL}$ spectra of $\mathrm{Sr}_{5} \mathrm{Mg}_{1-x} \mathrm{Mn}_{x}\left(\mathrm{La}_{0.99} \mathrm{Ce}_{0.01}\right)_{2}\left(\mathrm{BO}_{3}\right)_{6}$. Inset: integrated $\mathrm{PL}$ intensity in dependence of the $\mathrm{Ce}^{3+}$ and $\mathrm{Mn}^{2+}$ concentration.

$$
I(t)=A_{1} \mathrm{e}^{\frac{-t}{\tau_{1}}}+A_{2} \mathrm{e}^{\frac{-t}{\tau_{2}}}
$$

here, $I$ is the PL intensity at the time $t, A_{1}$ and $A_{2}$ are fitting parameters, and $\tau_{1}$ and $\tau_{2}$ are the partial fluorescence lifetimes of the exponential components. The bi-exponential behaviour of the PLD curves reflects PL of two different crystallographic sites as detailed above. The average fluorescence lifetimes $\tau$ of the $\mathrm{Ce}^{3+}$ emission were obtained applying eqn (3):

$$
\tau=\frac{A_{1} \tau_{1}^{2}+A_{2} \tau_{2}^{2}}{A_{1} \tau_{1}+A_{2} \tau_{2}}
$$

Calculated average fluorescence lifetimes $\tau$ as well as the emission fractions frac ${ }_{1}$ and $\mathrm{frac}_{2}$ are summarized in Table 1. It turned out that with increasing $\mathrm{Mn}^{2+}$ content fluorescence lifetimes $\tau$ of the $\mathrm{Ce}^{3+}$ emission decreases. Since ET processes are magnitudes faster than radiative transitions, this behaviour indicates the occurrence of ET from $\mathrm{Ce}^{3+}$ to $\mathrm{Mn}^{2+}$. The ET efficiency $\eta_{\mathrm{T}}$ can be calculated using the following equation: ${ }^{14}$

$$
\eta_{\mathrm{T}}=1-\frac{\tau_{\mathrm{S}}}{\tau_{\mathrm{S} 0}}
$$

here, $\tau_{\mathrm{S}}$ and $\tau_{\mathrm{S} 0}$ are the fluorescence lifetimes of $\mathrm{Ce}^{3+}$ in presence and absence of $\mathrm{Mn}^{2+}$. The calculated values for $\eta_{\mathrm{T}}$ are summarized in Table 1 and also plotted in the inset of Fig. 6. It can be seen that the values for $\eta_{\mathrm{T}}$ show a continuous growth with increasing $\mathrm{Mn}^{2+}$ content.

To identify the nature of the ET from $\mathrm{Ce}^{3+}$ to $\mathrm{Mn}^{2+}$ in codoped $\mathrm{Sr}_{5} \mathrm{La}{ }_{2} \mathrm{Mg}\left(\mathrm{BO}_{3}\right)_{6}: \mathrm{Ce}^{3+}, \mathrm{Mn}^{2+}$ Dexter's approach of exchange interactions and multipolar interactions was used.

On the basis of Dexter's ET formula and Reisfeld's approximation the following relations are obtained: ${ }^{15}$

$$
\begin{gathered}
\ln \left(\frac{\eta_{0}}{\eta}\right) \propto C \\
\frac{\eta_{0}}{\eta} \propto C^{\frac{\alpha}{3}}
\end{gathered}
$$




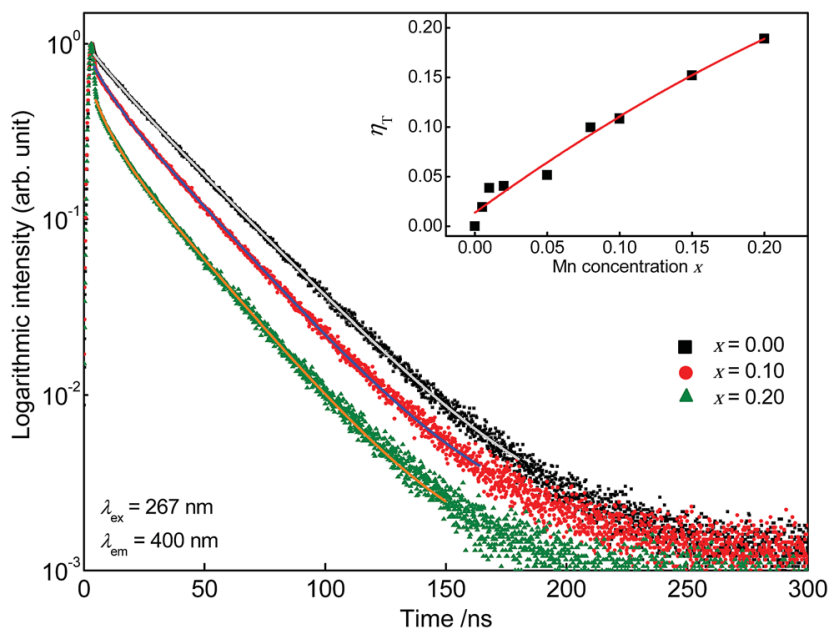

Fig. 6 PLD curves of $\mathrm{Sr}_{5} \mathrm{Mg}_{1-x} \mathrm{Mn}_{x}\left(\mathrm{La}_{0.99} \mathrm{Ce}_{0.01}\right)_{2}\left(\mathrm{BO}_{3}\right)_{6}$. Inset: ET transfer efficiency $\eta_{\mathrm{T}}$ in dependence of the $\mathrm{Mn}^{2+}$ concentration.

Table 1 Fluorescence lifetimes $\tau$ as well as partial lifetimes $\tau_{1}$ and $\tau_{2}$ and the emission fractions $\mathrm{frac}_{1}$ and $\mathrm{frac}_{2}$ of $\mathrm{Ce}^{3+}$ and ET efficiency $\eta_{\mathrm{T}}$ in $\mathrm{Sr}_{5} \mathrm{Mg}_{1-x} \mathrm{Mn}_{x}\left(\mathrm{La}_{0.99} \mathrm{Ce}_{0.01}\right)_{2}\left(\mathrm{BO}_{3}\right)_{6}$

\begin{tabular}{lllllll}
\hline $\begin{array}{l}\text { Sample } \\
(x)\end{array}$ & $\begin{array}{l}\text { frac }_{1} \\
(\%)\end{array}$ & $\begin{array}{l}\tau_{1} \\
(\mathrm{~ns})\end{array}$ & $\begin{array}{l}\mathrm{frac}_{2} \\
(\%)\end{array}$ & $\begin{array}{l}\tau_{2} \\
(\mathrm{~ns})\end{array}$ & $\begin{array}{l}\tau \\
(\mathrm{ns})\end{array}$ & \multicolumn{1}{l}{$\eta_{\mathrm{T}}$} \\
\hline 0.000 & 4 & 9.3 & 96 & 31.0 & 30 & 0 \\
0.005 & 5 & 9.4 & 95 & 30.7 & 30 & 0.02 \\
0.010 & 5 & 8.9 & 95 & 30.1 & 29 & 0.04 \\
0.020 & 4 & 7.5 & 96 & 30.0 & 29 & 0.04 \\
0.050 & 6 & 8.5 & 94 & 29.9 & 29 & 0.05 \\
0.080 & 7 & 6.9 & 93 & 28.7 & 27 & 0.10 \\
0.100 & 7 & 6.3 & 93 & 28.5 & 27 & 0.11 \\
0.150 & 11 & 7.6 & 89 & 27.8 & 26 & 0.15 \\
0.200 & 12 & 6.7 & 88 & 27.0 & 25 & 0.19 \\
& & & & & &
\end{tabular}

In these equations $\eta_{0}$ and $\eta$ are the internal luminescence quantum efficiencies of $\mathrm{Ce}^{3+}$ in the absence and presence of $\mathrm{Mn}^{2+}$. $C$ is the concentration of $\mathrm{Mn}^{2+}$ in the samples. Eqn (5) corresponds to exchange interaction whereas eqn (6) with $\alpha=6$, 8 , and 10 corresponds to dipole-dipole, dipole-quadrupole, and quadrupole-quadrupole interaction, respectively. $\eta_{0}$ and $\eta$ can approximately be estimated by the fluorescence lifetimes $\tau_{0}$ and $\tau$. Fig. 7 shows the plots of relation (5) and (6). A linear behaviour is only observed for relation (5) and suggests ET via exchange interaction.

To validate this result, the integrated PL intensities of the $\mathrm{Ce}^{3+}$ and $\mathrm{Mn}^{2+}$ emission were investigated using van Uitert's approach: $:^{16}$

$$
\frac{I}{I_{0}}=\left(1+A x^{\frac{\theta}{3}}\right)^{-1}
$$

here, $I$ and $I_{0}$ are the luminescence Intensities in the absence and presence of $\mathrm{Mn}^{2+}, A$ is a constant, and $x$ is the concentration of $\mathrm{Mn}^{2+}$ ions. $\theta=3,6,8$, and 10 represents exchange interaction, dipole-dipole, dipole-quadrupole, and quadrupolequadrupole interactions, respectively. ${ }^{17}$ Experimental data is plotted in Fig. 8 and best fitting is obtained when plugging in 3 for $\theta$. This also suggests that ET from $\mathrm{Ce}^{3+}$ to $\mathrm{Mn}^{2+}$ in $\mathrm{Sr}_{5} \mathrm{MgLa}_{2}\left(\mathrm{BO}_{3}\right)_{6}: \mathrm{Ce}^{3+}, \mathrm{Mn}^{2+}$ occurs via exchange interaction. This observation is rather uncommon for the ET from $\mathrm{Ce}^{3+}$ and $\mathrm{Mn}^{2+}$. Since exchange interactions proceed only over short distances this result implies a non-statistical distribution of the $\mathrm{Ce}^{3+}$ and $\mathrm{Mn}^{2+}$ ions. To estimate the critical distance between $\mathrm{Ce}^{3+}$ and $\mathrm{Mn}^{2+}$ further investigations were carried out using the Inokuti-Hirayama equation for exchange interaction: ${ }^{18}$

$$
\frac{I(t)}{I_{0}}=\exp \left[-\left(\frac{t}{\tau}\right)-\left(\frac{C}{C_{0}}\right) \gamma^{-3} g(z)\right]
$$

In this equation $I(t)$ is the intensity at a certain time and $I_{0}$ is the intensity after excitation. $t$ is the time and $\tau$ is the intrinsic fluorescence lifetime of $\mathrm{Ce}^{3+}$ in absence of $\mathrm{Mn}^{2+}$. $C$ is the concentration of $\mathrm{Mn}^{2+}$ ions per unit volume and $C_{0}$ is the critical concentration. $\gamma$ is the transfer volume and $g(z)$ is defined as

$$
g(z)=-z \int_{0}^{1} \exp (-z y)(\ln y)^{3} \mathrm{~d} y
$$

here, $z$ and $y$ are defined as

$$
z=\exp \left(\gamma \frac{t}{\tau}\right)
$$
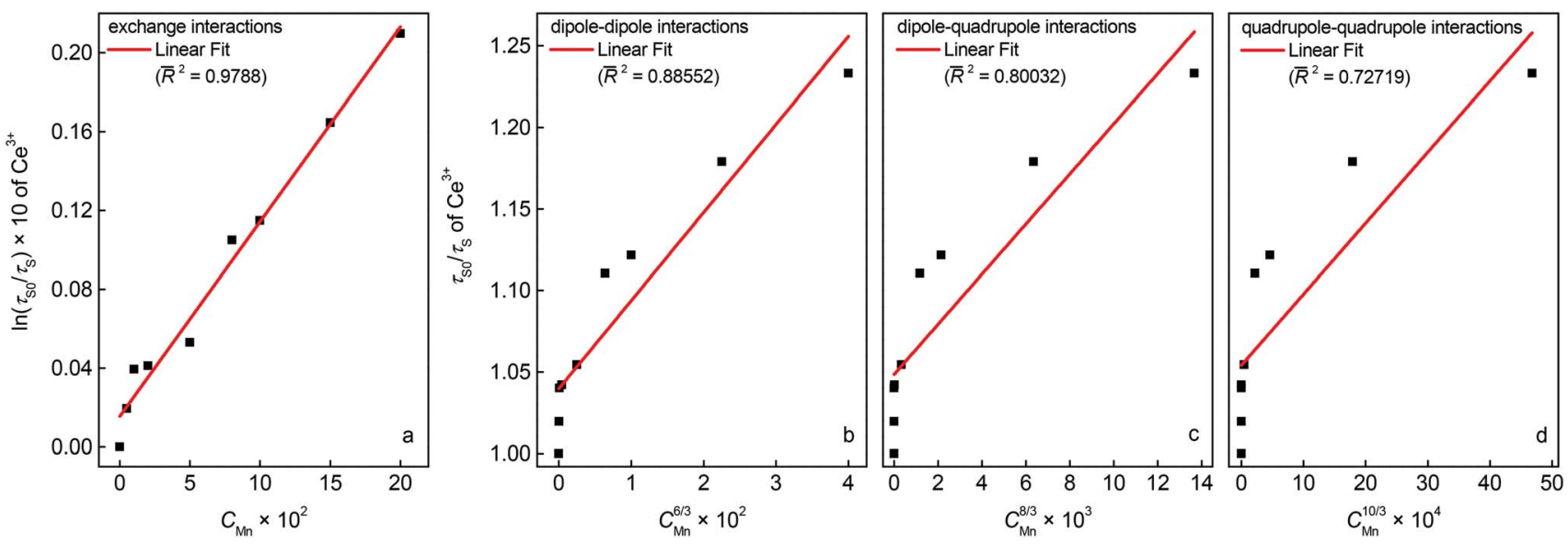

Fig. 7 Dependence of $\ln \left(\tau_{0} / \tau\right)$ on $C_{M n}(a)$ and $\tau_{0} / \tau$ on $C^{6 / 3}(b), C^{8 / 3}(c)$, and $C^{10 / 3}(d)$. 


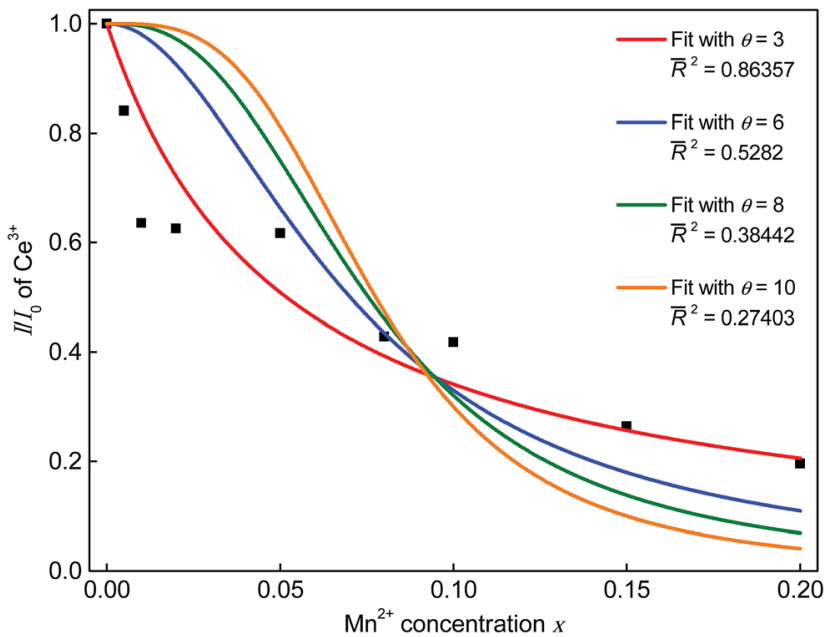

Fig. 8 Dependence of $/ / I_{0}$ on the $\mathrm{Mn}^{2+}$ concentration.

$$
y=\exp \left(-\gamma \frac{R}{R_{0}}\right)
$$

Eqn (9) can be expressed by a Taylor series as described by Inokuti and Hirayama which converges. This leads to the following formula:

$$
\begin{aligned}
\frac{I(t)}{I_{0}}= & \exp \left[-\left(\frac{t}{\tau}\right)-\left(\frac{C}{C_{0}}\right) \gamma^{-3} \times\left((\ln z)^{3}\right.\right. \\
& \left.\left.+h_{1}(\ln z)^{2}+h_{2}(\ln z)+h_{3}\right)\right]
\end{aligned}
$$

For the coefficients $h_{1}, h_{2}$, and $h_{3}$ the values 1.73164699, 5.93433597, and 5.44487446, respectively, given by Inokuti and Hirayama were plugged in. Fitting the PLD curves of the investigated samples with eqn (12) yields the $C / C_{0}$ values. $C / C_{0}$ values are plotted against $3 /\left(4 \pi R_{\mathrm{c}}{ }^{3}\right)$ in Fig. 9. Since $C_{0}=$ $3 /\left(4 \pi R_{\mathrm{c}}{ }^{3}\right)$, the slope of a linear fit through the data points is equal to $R_{\mathrm{c}}{ }^{3}{ }^{18,19}$ Therefore, the critical distance $R_{\mathrm{c}}$ for ET from $\mathrm{Ce}^{3+}$ to $\mathrm{Mn}^{2+}$ was calculated to be $4.6 \AA$.

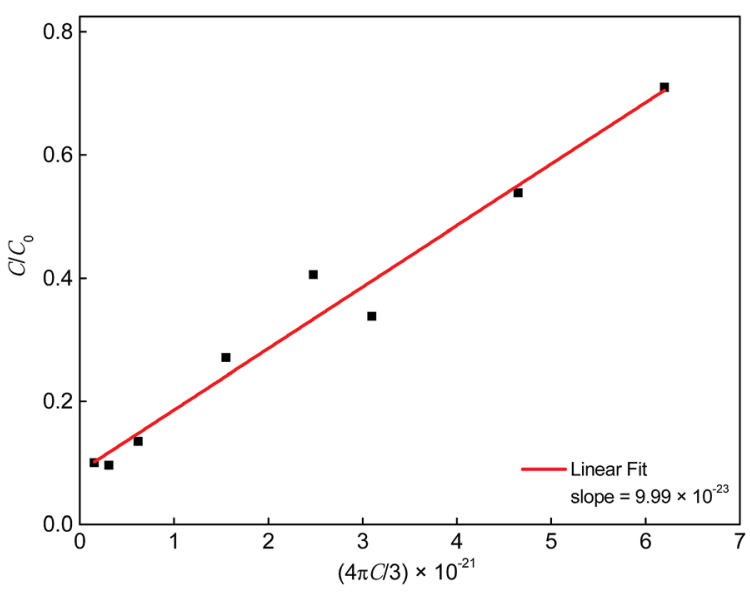

Fig. 9 Dependence of $C / C_{0}$ on $4 \pi C / 3$.
To investigate the temperature behaviour of the PL of $\mathrm{Sr}_{5} \mathrm{Mg}_{0.90} \mathrm{Mn}_{0.10}\left(\mathrm{La}_{0.99} \mathrm{Ce}_{0.01}\right)_{2}\left(\mathrm{BO}_{3}\right)_{6}$ PL spectra from 100 to $500 \mathrm{~K}$ were recorded. The obtained PL spectra are illustrated in Fig. 10. Due to thermal quenching, the PL intensity of $\mathrm{Ce}^{3+}$ and $\mathrm{Mn}^{2+}$ decreases with increasing temperature. In addition, the maximum of the $\mathrm{Mn}^{2+}$ emission band shows a shift towards higher energy of the electromagnetic spectrum. Since the equilibrium distance between the $\mathrm{Mn}^{2+}$ ions and its oxygen ligands extends with increasing temperature, the energy difference of the ${ }^{4} \mathrm{~T}_{1}\left({ }^{4} \mathrm{G}\right) \rightarrow{ }^{6} \mathrm{~A}_{1}\left({ }^{6} \mathrm{~S}\right)$ transition increases. ${ }^{20}$ Therefore, the maximum of the $\mathrm{Mn}^{2+}$ emission is shifted towards the blue range. The inset of Fig. 10 depicts the PL integrals of the $\mathrm{Ce}^{3+}$ and $\mathrm{Mn}^{2+}$ emission bands in dependence of temperature. By fitting the data points with a Fermi-Dirac distribution activation energy $E_{\mathrm{A}}$ for thermal quenching can be calculated.

$$
I(T)=\frac{I_{0}}{1+B \times \mathrm{e}^{\frac{-E_{\mathrm{A}}}{k T}}}
$$

here, $I(T)$ is the integrated PL intensity at a certain temperature and $I_{0}$ is the PL intensity at zero Kelvin. $B$ is the frequency factor for thermal quenching, $T$ is the temperature and $k$ is the Boltzmann constant $\left(k=8.617 \times 10^{-5} \mathrm{eV} \mathrm{K}^{-1}\right)$. The values of the parameters $I_{0}$ and $B$ were derived from the fitting function and are about 0.95 and 333, respectively. Fitting the data points with this equation yields an activation energy of $E_{\mathrm{A}}=0.18 \mathrm{eV}$. From this the $T_{1 / 2}$ value can be derived by using the following relation:

$$
T_{1 / 2}=\frac{-E_{\mathrm{A}}}{k \times \ln \left(\frac{1}{B}\right)}
$$

$T_{1 / 2}$ describes the temperature at which PL intensity of a luminescent centre is decreased to one-half of its maximum intensity. For the investigated $\mathrm{Sr}_{5} \mathrm{Mg}_{0.90} \mathrm{Mn}_{0.10}\left(\mathrm{La}_{0.99} \mathrm{Ce}_{0.01}\right)_{2}\left(\mathrm{BO}_{3}\right)_{6}$ sample $T_{1 / 2}$ was calculated to be $355 \mathrm{~K}$.

For further investigations on the origin of thermal quenching in $\mathrm{Sr}_{5} \mathrm{Mg}_{0.90} \mathrm{Mn}_{0.10}\left(\mathrm{La}_{0.99} \mathrm{Ce}_{0.01}\right)_{2}\left(\mathrm{BO}_{3}\right)_{6}$ fluorescence lifetime

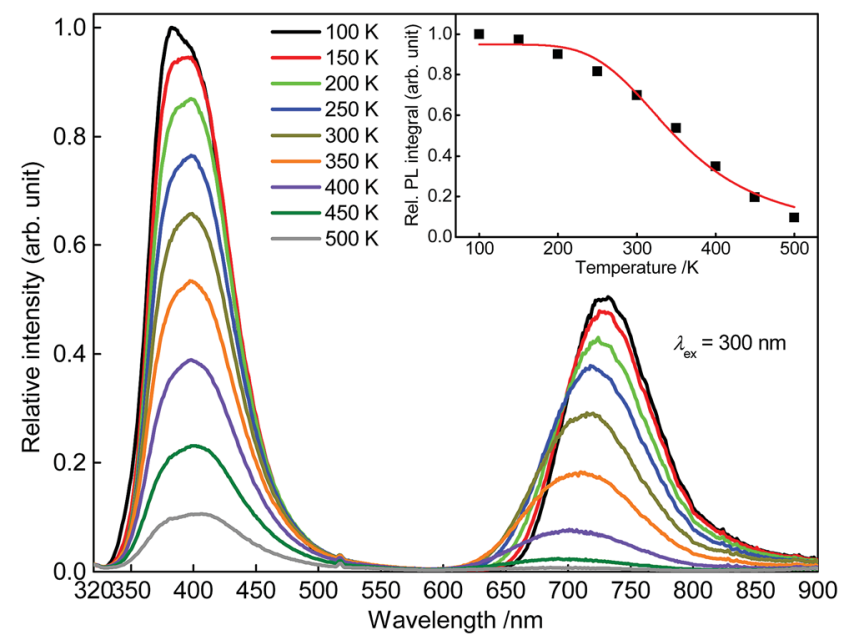

Fig. $10 \mathrm{PL}$ spectra of $\mathrm{Sr}_{5} \mathrm{Mg}_{0.90} \mathrm{Mn}_{0.10}\left(\mathrm{La}_{0.99} \mathrm{Ce}_{0.01}\right)_{2}\left(\mathrm{BO}_{3}\right)_{6}$ from 100 to 500. Inset: integrated PL intensity in dependence of temperature. 


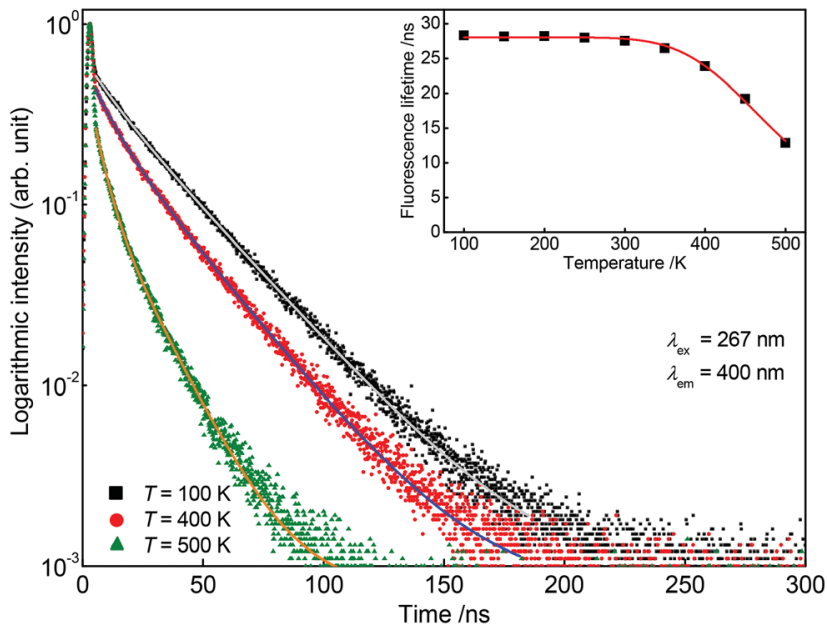

Fig. 11 Obtained PLD curves of $\mathrm{Sr}_{5} \mathrm{Mg}_{0.90} \mathrm{Mn}_{0.10}\left(\mathrm{La}_{0.99} \mathrm{Ce}_{0.01}\right)_{2}\left(\mathrm{BO}_{3}\right)_{6}$ at 100,400 , and $500 \mathrm{~K}$ monitoring the $\mathrm{PL}$ of $\mathrm{Ce}^{3+}$. Inset: Fluorescence lifetimes of the $\mathrm{Ce}^{3+}$ emission in dependence of temperature.

measurements were performed. Therefore, PLD curves of the $\mathrm{Ce}^{3+}$ as well as of the $\mathrm{Mn}^{2+}$ emission were recorded from 100 to 500 K. Fig. 11 depicts the obtained PLD curves monitoring the $400 \mathrm{~nm}$-emission of $\mathrm{Ce}^{3+}$. The PLD curves show a bi-exponential behaviour reflecting PL from two distinct crystallographic sites as mentioned above. The fluorescence lifetimes of $\mathrm{Ce}^{3+}$ are illustrated in the inset of Fig. 11 and are summarized in Table 2. From this finding it can be derived that the fluorescence lifetimes remain stable up to a temperature of $300 \mathrm{~K}$. At $350 \mathrm{~K}$ the fluorescence lifetimes start to decrease indicating a decline of radiative transitions due to thermal quenching. Fig. 12 shows the PLD curves of $\mathrm{Mn}^{2+}$ monitoring the emission at $725 \mathrm{~nm}$. It is obvious from the inset that the $\mathrm{Mn}^{2+}$ PL lifetimes decrease continuously over the complete temperature range. Fitting the fluorescence lifetimes of $\mathrm{Ce}^{3+}$ and $\mathrm{Mn}^{2+}$ with eqn (13) yields the $T_{1 / 2}$ values for the $\mathrm{Ce}^{3+}\left(T_{1 / 2, \mathrm{Ce}}\right)$ and $\mathrm{Mn}^{2+}\left(T_{1 / 2, \mathrm{Mn}}\right)$ emission. $T_{1 / 2, \mathrm{Ce}}$ and $T_{1 / 2, \mathrm{Mn}}$ were calculated to be 492 and $323 \mathrm{~K}$, respectively. This result indicates that the overall thermal quenching of the PL in $\operatorname{Sr}_{5} \mathrm{Mg}_{0.90} \mathrm{Mn}_{0.10}\left(\mathrm{La}_{0.99} \mathrm{Ce}_{0.01}\right)_{2}\left(\mathrm{BO}_{3}\right)_{6}$ is mainly caused by the presence of $\mathrm{Mn}^{2+}$.

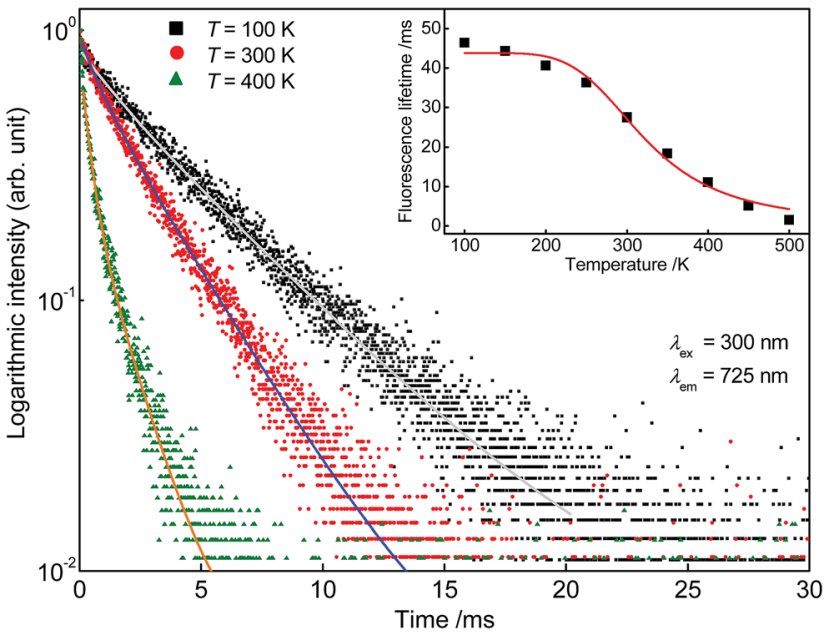

Fig. 12 Obtained PLD curves of $\mathrm{Sr}_{5} \mathrm{Mg}_{0.90} \mathrm{Mn}_{0.10}\left(\mathrm{La}_{0.99} \mathrm{Ce}_{0.01}\right)_{2}\left(\mathrm{BO}_{3}\right)_{6}$ at 100,300 , and $400 \mathrm{~K}$ monitoring the $\mathrm{PL}$ of $\mathrm{Mn}^{2+}$. Inset: Fluorescence lifetimes of the $\mathrm{Mn}^{2+}$ emission in dependence of temperature.

The efficiency of the prepared $\mathrm{Sr}_{5} \mathrm{MgLa}_{2}\left(\mathrm{BO}_{3}\right)_{6}: \mathrm{Ce}^{3+}, \mathrm{Mn}^{2+}$ samples was examined by determining external quantum efficiency $\eta_{\text {ext }}$ as mentioned above. To our understanding, $\eta_{\text {ext }}$ is defined as the ratio between the number of emitted photons $N_{\text {emission }}$ and the number of absorbed photons $N_{\text {absorption: }}$

$$
\eta_{\text {ext }}=\frac{N_{\text {emission }}}{N_{\text {absorption }}}
$$

The calculated external quantum efficiencies are summarized in Table 3. It turned out that with increasing $\mathrm{Mn}^{2+}$ concentration $\eta_{\text {ext }}$ continuously decreases. This is probably caused by concentration quenching due to ET between the $\mathrm{Mn}^{2+}$ ions.

To illustrate the colour of the emission, CIE chromaticity coordinates were calculated according to the relevant PL spectra. The obtained colour points are depicted in Fig. 13. All colour points are located in the violet region of the chromaticity coordinates diagram. With increasing $\mathrm{Mn}^{2+}$ content the colour points show a shift towards the red region. Since the $\mathrm{Mn}^{2+}$

Table 2 Fluorescence lifetimes $\tau$ as well as partial lifetimes $\tau_{1}$ and $\tau_{2}$ and the emission fractions frac $_{1}$ and frac $_{2}$ of $\mathrm{Ce}^{3+}$ and $\mathrm{Mn}^{2+}$ in $\mathrm{Sr}_{5} \mathrm{Mg}_{1-x} \mathrm{Mn}_{x}\left(\mathrm{La}_{0.99} \mathrm{Ce}_{0.01}\right)_{2}\left(\mathrm{BO}_{3}\right)_{6}$ from 100 to $500 \mathrm{~K}$

\begin{tabular}{|c|c|c|c|c|c|c|c|c|c|c|}
\hline \multirow[b]{2}{*}{$T(\mathrm{~K})$} & \multicolumn{5}{|l|}{$\mathrm{Ce}^{3+}$} & \multicolumn{5}{|l|}{$\mathrm{Mn}^{2+}$} \\
\hline & $\tau_{1}(\mathrm{~ns})$ & $\operatorname{frac}_{1}(\%)$ & $\tau_{2}(\mathrm{~ns})$ & $\operatorname{frac}_{2}(\%)$ & $\tau(\mathrm{ns})$ & $\tau_{1}(\mathrm{~ms})$ & $\operatorname{frac}_{1}(\%)$ & $\tau_{2}(\mathrm{~ms})$ & $\operatorname{frac}_{2}(\%)$ & $\tau(\mathrm{ms})$ \\
\hline 150 & 9.6 & 7 & 29.6 & 93 & 28 & 13.1 & 5 & 45.9 & 95 & 44 \\
\hline 200 & 10.2 & 9 & 30.0 & 91 & 28 & 16.5 & 9 & 42.9 & 91 & 41 \\
\hline 250 & 8.7 & 7 & 29.5 & 93 & 28 & 16.8 & 13 & 37.9 & 87 & 35 \\
\hline 400 & 9.1 & 17 & 26.8 & 83 & 24 & 3.5 & 27 & 13.8 & 73 & 11 \\
\hline 450 & 7.2 & 21 & 22.4 & 79 & 19 & 1.7 & 30 & 6.5 & 70 & 5 \\
\hline 500 & 4.8 & 29 & 16.2 & 71 & 13 & 0.3 & 12 & 1.7 & 88 & 2 \\
\hline
\end{tabular}


Table 3 External quantum efficiencies $\eta_{\text {ext }}$ and $\mathrm{CIE}$ colour coordinates of $\mathrm{Sr}_{5} \mathrm{Mg}_{1-x} \mathrm{Mn}_{x}\left(\mathrm{La}_{0.99} \mathrm{Ce}_{0.01}\right)_{2}\left(\mathrm{BO}_{3}\right)_{6}$

\begin{tabular}{lll}
\hline Sample $(x)$ & $\eta_{\text {ext }}$ & CIE $(x \mid y)$ \\
\hline 0.000 & 0.97 & $(0.160 \mid 0.046)$ \\
0.005 & 0.72 & $(0.160 \mid 0.046)$ \\
0.010 & 0.53 & $(0.161 \mid 0.046)$ \\
0.020 & 0.57 & $(0.164 \mid 0.048)$ \\
0.050 & 0.53 & $(0.169 \mid 0.050)$ \\
0.080 & 0.33 & $(0.175 \mid 0.052)$ \\
0.100 & 0.33 & $(0.178 \mid 0.052)$ \\
0.150 & 0.20 & $(0.194 \mid 0.062)$ \\
0.200 & 0.18 &
\end{tabular}

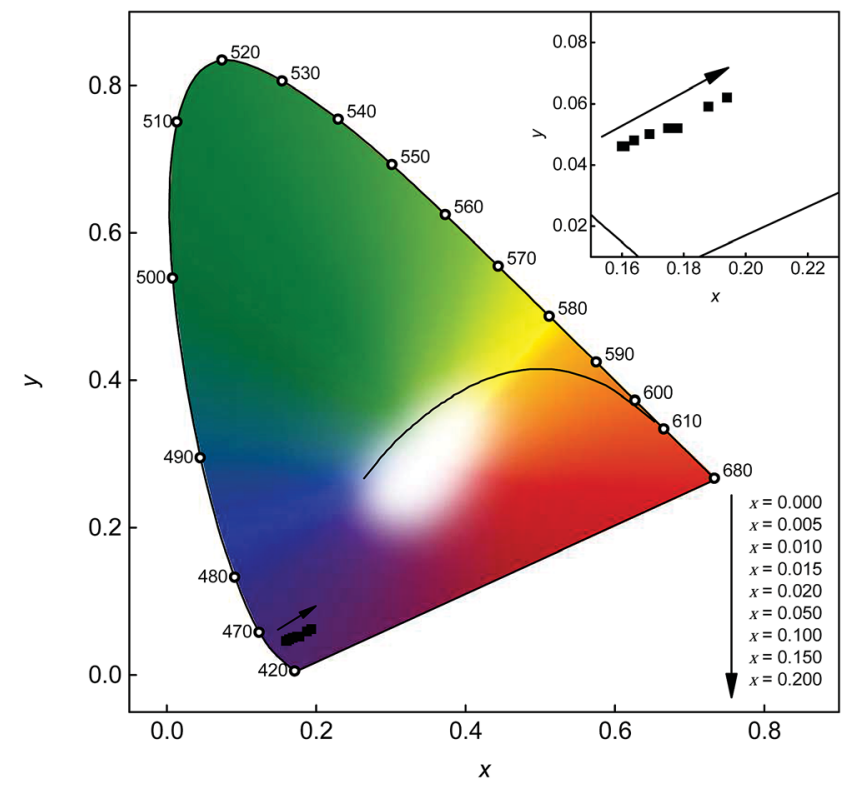

Fig. $13 \mathrm{ClE}$ chromaticity diagram of $\mathrm{Sr}_{5} \mathrm{Mg}_{1-x} \mathrm{Mn}_{x}\left(\mathrm{La}_{0.99} \mathrm{Ce}_{0.01}\right)_{2}\left(\mathrm{BO}_{3}\right)_{6}$ with different $\mathrm{Mn}^{2+}$ concentrations. Inset: Enlarged section of the relevant range.

emission band is located in the deep red range of the visible spectrum where the eye sensitivity is rather low, the observed shift of the colour points is rather low too. A larger shift into the red region of the chromaticity coordinates diagram using co-doped $\mathrm{Sr}_{5} \mathrm{MgLa}_{2}\left(\mathrm{BO}_{3}\right)_{6}: \mathrm{Ce}^{3+}, \mathrm{Mn}^{2+}$ could be obtained using a lower $\mathrm{Ce}^{3+}$ content. In this way the $\mathrm{Mn}^{2+}$ emission would be more intense compared to the $\mathrm{Ce}^{3+}$ emission band resulting in a larger shift.

\section{Conclusions}

To investigate the PL properties and the ET between $\mathrm{Ce}^{3+}$ and $\mathrm{Mn}^{2+}$ of co-doped $\mathrm{Sr}_{5} \mathrm{MgLa}_{2}\left(\mathrm{BO}_{3}\right)_{6}: \mathrm{Ce}^{3+}, \mathrm{Mn}^{2+}$ a series of powder samples with various $\mathrm{Mn}^{2+}$ contents was prepared. $\mathrm{Sr}_{5} \mathrm{MgLa}_{2}\left(\mathrm{BO}_{3}\right)_{6}: \mathrm{Ce}^{3+}, \mathrm{Mn}^{2+}$ shows two emission bands located at 403 and $713 \mathrm{~nm}$ upon excitation at $\lambda_{\mathrm{ex}}=300 \mathrm{~nm}$. Low temperature PL measurement on the $\mathrm{Ce}^{3+}$ emission reveals that the $\mathrm{Ce}^{3+}$ ions mainly occupy the 9-fold coordinated sites as well as the 6-fold coordinated $\mathrm{Sr}^{2+}$ sites. This statement is backed by the bi-exponential PLD curves of $\mathrm{Sr}_{5} \mathrm{Mg}\left(\mathrm{La}_{0.99} \mathrm{Ce}_{0.01}\right)_{2}\left(\mathrm{BO}_{3}\right)_{6}$. The highest PL intensity was found for a $\mathrm{Mn}^{2+}$ content of $x=0.100$. Furthermore, it was demonstrated that the ET from $\mathrm{Ce}^{3+}$ to $\mathrm{Mn}^{2+}$ occurs via an exchange interaction mechanism. Critical distance $R_{\mathrm{c}}$ was determined to be $4.6 \AA$. Temperature depended PL measurements prove a $T_{1 / 2}$ value of $355 \mathrm{~K}$ for $\mathrm{Sr}_{5} \mathrm{Mg}_{0.90} \mathrm{Mn}_{0.10}\left(\mathrm{La}_{0.99} \mathrm{Ce}_{0.01}\right)_{2}\left(\mathrm{BO}_{3}\right)_{6}$. Furthermore, temperature dependent fluorescence lifetimes revealed that thermal quenching is mainly caused by the $\mathrm{Mn}^{2+}$ ions. Finally, the external quantum efficiencies $\eta_{\text {ext }}$ were determined to be close to unity of the $\mathrm{Ce}^{3+}$ doped samples. With increasing $\mathrm{Mn}^{2+} \eta_{\text {ext }}$ continuously decreases. Calculated chromaticity coordinates are all located in the violet region of the CIE diagram. Therefore, codoped $\mathrm{Sr}_{5} \mathrm{MgLa}_{2}\left(\mathrm{BO}_{3}\right)_{6}: \mathrm{Ce}^{3+}, \mathrm{Mn}^{2+}$ with the herein investigated doping levels is not suitable as a white or red emitting phosphor.

\section{Acknowledgements}

The authors are grateful to Merck KGaA Darmstadt, Germany for generous financial support.

\section{References}

1 (a) C. Feldmann, T. Jüstel, C. R. Ronda and P. J. Schmidt, Adv. Funct. Mater., 2003, 13, 511-516; (b) E. F. Schubert and J. K. Kim, Science, 2005, 308, 1274-1278.

2 S. Nakamura, P. Stephen and F. Gerhard, The Blue Laser Diode: The Complete Story, Springer-Verlag, Berlin/ Heidelberg, 1997.

3 H. S. Jang, W. B. Im, D. C. Lee, D. Y. Jeon and S. S. Kim, J. Lumin., 2007, 126, 371-377.

4 Y. Uchida and T. Taguchi, Opt. Eng., 2005, 44, 124003.

5 M. Shang, C. Li and J. Lin, Chem. Soc. Rev., 2014, 43, 1372.

6 (a) M. Müller and T. Jüstel, J. Lumin., 2014, 155, 398-404; (b) T. Jia, Z. Ci, Q. Wu, G. Zhu, C. Wang and Y. Wang, ECS J. Solid State Sci. Technol., 2015, 4, R78-R82.

7 (a) R. Yu, H. Li, H. Ma, C. Wang, H. Wang and J. McKittrick, J. Am. Ceram. Soc., 2014, 97, 1151-1156; (b) Q. Liu, Y. Liu, Y. Ding, Z. Peng, Q. Yu, X. Tian and G. Dong, J. Sol-Gel Sci. Technol., 2014, 71, 276-282; (c) Y. Shi, Y. Wen, M. Que, G. Zhu and Y. Wang, Dalton Trans., 2014, 2418-2423; (d) L. Wu, B. Wang, Y. Zhang, L. Li, H. R. Wang, H. Yi, Y. F. Kong and J. J. Xu, Dalton Trans., 2014, 13845.

8 K. I. Schaffers, P. D. Thompson, T. Alekel III, J. R. Cox and D. A. Keszler, Chem. Mater., 1994, 6, 2014-2022.

9 R. Sankar and G. Subba Rao, J. Alloys Compd., 1998, 281, 126136.

10 R. Sankar, Solid State Sci., 2008, 10, 1864-1874.

11 R. D. Shannon, Acta Crystallogr., Sect. A: Cryst. Phys., Diffr., Theor. Gen. Crystallogr., 1976, 32, 751-767.

12 Y. Kawamura, H. Sasabe and C. Adachi, Jpn. J. Appl. Phys., 2004, 43, 7729-7730.

13 (a) F. A. Kröger and J. Bakker, Physica, 1941, 8, 628-646; (b) G. Blasse and A. Bril, J. Chem. Phys., 1967, 47, 5139-5145.

14 (a) H. C. Kandpal and H. B. Tripathi, Indian J. Pure Appl. Phys., 1979, 17, 587-589; (b) P. Paulose, G. Jose, V. Thomas, N. Unnikrishnan and M. Warrier, J. Phys. Chem. Solids, 2003, 64, 841-846. 
15 (a) D. L. Dexter, J. Chem. Phys., 1953, 21, 836; (b) D. L. Dexter and J. H. Schulman, J. Chem. Phys., 1954, 22, 1063; (c) R. Reisfeld, E. Greenberg, R. Velapoldi and B. Barnett, J. Chem. Phys., 1972, 56, 1698.

16 L. G. van Uitert, J. Electrochem. Soc., 1967, 114, 1048.
17 (a) L. Zhang, Z. Lu, P. Han, L. Wang and Q. Zhang, J. Nanomater., 2012, 2012, 1-7; (b) F. Zhang and W. Tang, Luminescence, 2015, 30, 216-220.

18 M. Inokuti and F. Hirayama, J. Chem. Phys., 1965, 43, 1978. 19 J. S. Lee, S. Unithrattil and W. B. Im, J. Alloys Compd., 2013, 555, 297-303.

20 Y. Tanabe and S. Sugano, J. Phys. Soc. Jpn., 1954, 9, 766-779. 